\title{
The Molecular Mechanism of Alpha- Synuclein Dependent Regulation of Protein Phosphatase 2A Activity
}

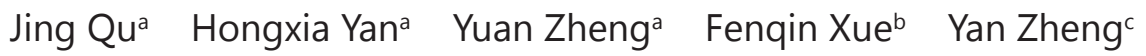 \\ Hongjuan Fang ${ }^{d}$ Yongchang Change Hui Yang ${ }^{\text {a }}$ Jianliang Zhang ${ }^{\mathrm{a}}$ \\ aDepartment of Neurobiology, Beijing Institute of Brain Disorders, Capital Medical University, Key \\ Laboratory for Neurodegenerative Disease of the Ministry of Education, Beijing Key Laboratory of \\ Neural Regeneration and Repairing, Beijing Key Laboratory of Brain Major Disorders-State Key Lab \\ Incubation Base, Beijing Neuroscience Disciplines, Beijing, ${ }^{\text {bC } C o r e ~ F a c i l i t i e s ~ C e n t e r, ~ C a p i t a l ~ M e d i c a l ~}$ \\ University, Beijing, 'Department of Physiology, Capital Medical University, Beijing, dDepartment \\ of Endocrinology, Beijing Tiantan Hospital, Capital Medical University, Beijing, China, eDivision of \\ Neurobiology, Barrow Neurological Institute, St. Joseph's Hospital and Medical Center, Phoenix, USA
}

\section{Key Words}

Alpha-synuclein - Protein phosphatase 2A • Parkinson's disease

\begin{abstract}
Background/Aims: Alpha-synuclein ( $\alpha$-Syn) is a neuronal protein that is highly implicated in Parkinson's disease (PD), and protein phosphatase 2A (PP2A) is an important serine/threonine phosphatase that is associated with neurodegenerative diseases, such as PD. $\alpha$-Syn can directly upregulate PP2A activity, but the underling mechanism remains unclear. Therefore, we investigated the molecular mechanism of $\alpha$-Syn regulating PP2A activity. Methods: $\alpha$-Syn and its truncations were expressed in E.coli, and purified by affinity chromatography. PP2A $\mathrm{C} \alpha$ and its mutants were expressed in recombinant baculovirus, and purified by affinity chromatography combined with gel filtration chromatography. The interaction between $\alpha$-Syn and PP2A C $\alpha$ was detected by GST pull-down assay. PP2A activity was investigated by the colorimetric assay. Results: The hydrophobic non-amyloid component (NAC) domain of $\alpha$-Syn interacted with PP2A C $\alpha$ and upregulated its activity. $\alpha$-Syn aggregates reduced its ability to upregulate PP2A activity, since the hydrophobic domain of $\alpha$-Syn was blocked during aggregation. Furthermore, in the hydrophobic center of PP2A C $\alpha$, the residue of I123 was responsible for PP2A to interact with $\alpha$-Syn, and its hydrophilic mutation blocked its interaction with $\alpha$-Syn as well as its activity upregulation by $\alpha$-Syn. Conclusions: $\alpha$-Syn bound to PP2A C $\alpha$ by the hydrophobic interaction and upregulated its activity. Blocking the hydrophobic domain of $\alpha$-Syn or hydrophilic mutation on the residue I123 in PP2A C $\alpha$ all reduced PP2A activity upregulation by $\alpha$-Syn. Overall, we explored the mechanism of $\alpha$-Syn regulating PP2A activity, which might offer much insight into the basis underlying PD pathogenesis.
\end{abstract}

\begin{tabular}{ll} 
& $\begin{array}{c}\text { (c) } 2018 \text { The Author(s) } \\
\text { Published by S. Karger AG, Basel }\end{array}$ \\
\hline Dr. Jianliang Zhang & Department of Neurobiology, Capital Medical University \\
& 10 Xitoutiao, Youanmenwai, Beijing 100069 (China) \\
Tel. +8610 83911491, E-Mail jlzhang@ccmu.edu.cn
\end{tabular}




\section{Cellular Physiology Cell Physiol Biochem 2018;47:2613-2625 \begin{tabular}{l|l} 
DOI: 10.1159/000491657 & a 2018 The Author(s). Published by S. Karger AG, Basel \\
www.karger.com/cpb
\end{tabular}}

Qu et al.: Alpha-Synuclein Upregulating Protein Phosphatase 2A Activity

\section{Introduction}

Alpha-synuclein ( $\alpha$-Syn), encoded by the SNCA gene [1-3], contributes to brain neuroplasticity and neurodegeneration, which is implicated as being causative factor for neurodegenerative disorders, including Parkinson's disease (PD), dementia with Lewy bodies (DLB), as well as multiple system atrophy (MSA) [4-6]. $\alpha$-Syn is abundantly expressed in the central nervous system, mainly at presynaptic terminal in mammalian brains. Structurally, $\alpha$-Syn can usually be divided into three parts: the $\mathrm{N}$ terminus (residues 1-60), which contain four 11-amino acid imperfect repeats (coding for amphipathic $\alpha$-helices) with a conserved motif (KTKEGV); the central hydrophobic non-amyloid component (NAC, residues 61-95), which contain three additional KTKEGV repeats; and the C terminus (residues 96-140), in which acidic residues and prolines are highly enriched [7-9]. The $\mathrm{N}$ terminus, with lipidbinding motifs KTKEGV, is predicated to form $\alpha$-helical structure for interaction with lipidic membranes $[7,10,11]$. Most of the mutants associated with PD, such as A53T, exist in this region [12]. The NAC domain is responsible for its misfolding and aggregation $[8,13]$. The $\mathrm{C}$ terminus is thought to contain protein-protein and protein-small molecule interaction sites [14-16]. $\alpha$-Syn not only regulates the release of neurotransmitters, but also regulates the activity of many proteins, such as protein phosphatase 2A (PP2A)[17-19].

PP2A is an important serine/threonine phosphatase, and it is comprised of three subunits: a $65-\mathrm{kD}$ structural subunit $\mathrm{A}$, a variable regulatory subunit $\mathrm{B}$, and a $36-\mathrm{kD}$ catalytic subunit $C$ [20-25], and the subunit $C$ has a unique catalytic activity. PP2A can directly dephosphorylate numerous substrates, such as tyrosine hydroxylase (TH) [26, 27], extracellular-regulated kinases (ERK1/2) [28], and tau protein [29-31]. PP2A is a key regulator in neurodegenerative diseases [32-36]. In Alzheimer's disease (AD), the downregulation of PP2A activity could increase the phosphorylation of tau protein, raise the formation of amyloid precursor protein, and increase the missing of neurons [37-39]. In PD, the upregulation of PP2A activity could reduce the phosphorylation of $\mathrm{TH}$, which leads to the decrease of dopamine [17].

Previous studies showed that $\alpha$-Syn could upregulate the activity of PP2A which further reduce $\mathrm{TH}$ phosphorylation in dopaminergic cells $[17,40]$, but the underlying structural mechanism of $\alpha$-Syn regulating PP2A activity remains unclear.

In this study, to gain insight into the precise manner by which $\alpha$-Syn bind to PP2A to stimulate its activity, we proposed a hypothesis that $\alpha$-Syn could bind to PP2A C $\alpha$ by the hydrophobic interaction and then upregulate its activity. To confirm our hypothesis, we firstly constructed $\alpha$-Syn truncates, and found that the NAC domain of $\alpha$-Syn interacted with PP2A C $\alpha$ and upregulated PP2A activity. Second, after blocking the NAC domain by forming $\alpha$-Syn aggregates, we found $\alpha$-Syn aggregates less stimulated PP2A activity than monomers. Finally, we defined the definite residue within PP2A C $\alpha$ which was responsible for its interaction with $\alpha$-Syn, and its association with PP2A activity regulation by $\alpha$-Syn. In short, the data showed that NAC domain of $\alpha$-Syn could bind to the hydrophobic center of PP2A C $\alpha$, particularly the residue I123, to stimulate PP2A activity. These results might offer insight into the mechanistic basis of PD pathogenesis.

\section{Materials and Methods}

\section{Plasmid constructs}

The cDNA encoding the $\alpha$-Syn and its truncates were subcloned into the pCMV-myc vector. The mutants of $\alpha$-Syn (A53T) and PP2A C $\alpha$ (I123S, W200S, L243S, Y265S and C269S) were performed using the PCR-based Quik Change method of site-directed mutagenesis with Phusion DNA polymerase (Agilent Technologies). These mutations were confirmed by sequencing the entire coding region.

To make $\alpha$-Syn-GLuc constructs, $\alpha$-Syn was subcloned into the fragments of humanized Gaussia princeps luciferase (1-93; 94-169) to generate $\alpha$-Syn-GLuc-N and $\alpha$-Syn-GLuc-C fusion constructs. For the A53T-GLuc-N and A53T-GLuc-C fusion constructs, they were generated by the similar method. 


\section{Cellular Physiology Cell Physiol Biochem 2018;47:2613-2625 $\begin{array}{lll}\text { DOI: 10.1159/000491657 } & \text { O } 2018 \text { The Author(s). Published by S. Karger AG, Basel } \\ \text { www.karger.com/cpb }\end{array}$}

Qu et al.: Alpha-Synuclein Upregulating Protein Phosphatase 2A Activity

\section{Cell cultures and transfection}

Human SK-N-SH neuroblastoma cells obtained from the American Type Culture Collection were grown in Dulbecco's Modified Eagle's Medium (DMEM, Gibco) supplemented with 10\% fetal bovine serum (FBS, Gibco) at $37^{\circ} \mathrm{C}$ under $5 \% \mathrm{CO}_{2}$. The transient transfections were performed by lipofection with polyetherimide (PEI, Polysciences).

\section{Western blot}

After transfection, cells were washed with ice-cold phosphate-buffered saline (PBS, Origene) and homogenized them in ice-cold lysis buffer (15 mM Tris, 0.25 M sucrose, 2 mM EDTA, 1 mM EGTA, $10 \mathrm{mM}$ $\mathrm{Na}_{3} \mathrm{VO}_{4}, 25 \mathrm{mM} \mathrm{NaF}, 10 \mathrm{mM}$ sodium pyrophosphate, and protease inhibitor, $\mathrm{pH}$ 7.6) for $30 \mathrm{~min}$. Then homogenates were centrifuged at 12, $000 \mathrm{~g}$ for $30 \mathrm{~min}$ and the supernatant fraction was collected for analysis. The protein concentration was determined using a bicinchoninic acid protein assay kit (Pierce Biotechnology) according to the manufacturer's instructions. The samples were resolved on $10 \%$ SDS polyacrylamide gels and transferred to PVDF membranes (Millpore). The membranes were probed with the following primary antibodies: mouse anti- $\beta$-actin $(1: 2,000$, GuanXingYu), mouse anti- $\alpha$-Syn $(1: 2000$, BD), mouse anti-myc (1:5000, Clontech). These primary antibodies were revealed by infrared-conjugated IgG IRDye 680RD (1:10000, LI-COR Bioscience) or 800CW (1:10000, LI-COR Bioscience). Protein bands were detected using an Odyssey Infrared Imaging system (LI-COR Bioscience), and analyzed with Image J software (imagej.nih.gov/ij/).

\section{Immunofluorescence and confocal microscopy}

$24 \mathrm{~h}$ after transfection with the indicated plasmids, SK-N-SH cells were washed with PBS, fixed with $4 \%$ paraformaldehyde for 20 min, washed in PBS again, and permeabilized with $0.3 \%$ Triton X-100 in PBS for $25 \mathrm{~min}$ at room temperature. After blocking with $10 \%$ normal goat serum for $1 \mathrm{~h}$, cells were incubated with mouse anti-myc $\left(1: 2000\right.$, Clontech) overnight at $4^{\circ} \mathrm{C}$, followed by incubation with Alexa Fluor 488-conjugated secondary antibody (1:500, Life Technologies) for $1 \mathrm{~h}$ at room temperature. Cell nuclei were visualized by staining with DAPI (1:1000, Sigma). The cells were imaged using a confocal microscope (Leica Microsystems).

\section{Protein expression and purification}

The cDNA encoding full-length $\alpha$-Syn and its truncates were subcloned into pGEX4T-1 vector (Invitrogen), and expressed in E.coli strain BL21 cells. $0.1 \mathrm{mM}$ Isopropyl $\beta$-D-galactopyranoside (IPTG) was added to bacterial cultures grown at $27^{\circ} \mathrm{C}$. The lysates were centrifuged at $12,000 \mathrm{~g}$ for $40 \mathrm{~min}$, then the supernatants were incubated with glutathione-sepharose $4 \mathrm{~B}$ beads (GE Healthcare) at $4^{\circ} \mathrm{C}$. After $3 \mathrm{~h}$, the beads were collected and washed 3 times. The GST fusion proteins were eluted by buffer containing $50 \mathrm{mM}$ Tris- $\mathrm{HCl}$ and $10 \mathrm{mM}$ reduced glutathione ( $\mathrm{pH}$ 8.0). The purified GST fusion proteins were stored at $-80^{\circ} \mathrm{C}$.

The cDNA encoding PP2A C $\alpha$ and its mutants were subcloned into pFastbac vector (Invitrogen), transformed into E.coli strain DH10Bac cells, and isolated the recombinant bacmid DNA. Then transfect recombinant bacmid DNA into SF9 cells, harvest the recombinant baculovirus, and express the baculovirus in SF9 cells. The cell lysates were harvested 3 days after infection with P2 baculovirus, and centrifuged at 12, $000 \mathrm{~g}$ for $15 \mathrm{~min}$, then the supernatants were incubated with Ni-Sepharose 6 beads (GE Healthcare) at $4^{\circ} \mathrm{C}$. After $2.5 \mathrm{~h}$, the beads were collected and washed 3 times. The His fusion proteins were eluted by buffer containing $50 \mathrm{mM}$ sodium phosphate, $300 \mathrm{mM} \mathrm{NaCl}$ and $300 \mathrm{mM}$ imidazole (pH 7.0). Then, the protein was further purified by gel filtration through a Superdex 75 column, during which the imidazole had been desalted, and the buffer was exchanged into Tris buffer (50 mM Tris- $\mathrm{HCl}, \mathrm{pH}$ 8). The purified His fusion proteins were finally concentrated by Amicon Ultra-4 Centrifugal Filter Devices (Merck Millipore) and stored at $-80^{\circ} \mathrm{C}$.

PP2A activity assay

The activity of PP2A was measured using a PP2A Colorimetric Assay kit (GenMed Scientifics Inc). This assay is based on the release of free phosphate during the dephosphorylation of RKpTIRR by endogenous PP2A, detected by a chromogenic reaction with molybdenum blue produced by a ferrous sulfate reduction. In brief, samples were incubated for $20 \mathrm{~min}$ at $30^{\circ} \mathrm{C}$ in the assay buffer containing $50 \mathrm{mM}$ Tris- $\mathrm{HCl} \mathrm{pH} 8$, $0.1 \mathrm{mg} / \mathrm{ml}$ BSA, $1 \mathrm{mM} \beta$-mecaptoethanol (BME) and $40 \mu \mathrm{M}$ substrate RKpTIRR. To terminate the reaction, 


\section{Cellular Physiology Cell Physiol Biochem 2018;47:2613-2625 \begin{tabular}{l|l} 
DOI: 10.1159/000491657 & Ond Biochemistry \\
Publisned onnne: 2018 The Author(s). Published by S. Karger AG, Basel \\
www.karger.com/cpb
\end{tabular} \\ Qu et al.: Alpha-Synuclein Upregulating Protein Phosphatase 2A Activity}

molybdenum blue solution was added to the mixture. The mixture was incubated for 15 min at $30^{\circ} \mathrm{C}$ to allow color development. The free phosphate concentration was measured at $660 \mathrm{~nm}$ using a spectrophotometer (Bio-Rad), and the phosphate concentration was converted to PP2A activity/mg protein as described in the instructions.

GST pull-down assay

The GST pull-down assays were carried out as described $[41,42]$. In brief, the proteins with GST tag were incubated with glutathione beads for $1 \mathrm{~h}$ at $4^{\circ} \mathrm{C}$, and washed 5 times with PBS. Then PP2A C $\alpha$ or its mutants were subjected to GST pull-down with GST or GST fusion proteins for $3 \mathrm{~h}$ at $4^{\circ} \mathrm{C}$. The products were centrifuged at $1000 \mathrm{~g}$ for $5 \mathrm{~min}$ at $4^{\circ} \mathrm{C}$. Samples were washed 5 times with PBS. After the final wash, glutathione-bound proteins were eluted by adding of loading buffer and boiling for $10 \mathrm{~min}$. Eluted proteins were separated by SDS-PAGE gels with the corresponding antibodies, such as mouse anti-His (1:5000, Clontech) and mouse anti-GST (1:10000, Novagen).

\section{Transmission electron microscopy (TEM)}

$\alpha$-Syn aggregates were fixed on Formvar coated copper grids for 2 min, stained with $2 \%$ uranyl acetate solution for 5 min, washed in 0.1 M PBS for 3 times, air dried, and observed by a JEOL transmission electron microscope.

\section{Protein-fragment complementation assay}

Fusion constructs for $\alpha$-Syn ( $\alpha$-Syn-GLuc-N, $\alpha$-Syn-GLuc-C), and for A53T (A53T-GLuc-N, A53T-GLuc-C) were generated and the respective paired constructs were transfected into SK-N-SH cells in a 96-well plate format. $24 \mathrm{~h}$ after transfection, cells were washed with PBS and replaced with phenol-red free medium. Luciferase activity from protein complementation was measured for live cells in an automated plate reader at $480 \mathrm{~nm}$ following the injection of the cell permeable substrate, coelenterazine (20 $\mu \mathrm{M})$ (Sigma) with a signal integration time of $2 \mathrm{~s}$.

\section{Computational docking}

The computational model of the interaction between $\alpha$-Syn to PP2A C $\alpha$ was accomplished using online protein-protein dock server, ZDOCK 3.0.2 (http://zdock.umassmed.edu/). The amino acid sequences of human $\alpha$-Syn (PDBID: 1XQ8) and PP2A C $\alpha$ (PDBID: 2IAE chain C) were downloaded from the NCBI website, and uploaded to the server. The final image of the model was downloaded and visualized by Discovery Studio Visualizer 4.0 (BIOVIA, San Diego, CA, USA).

\section{Statistics}

Statistical analyses were performed using Prism software, version 6 (GraphPad). Differences between groups were assessed by ANOVA. Data are expressed as mean \pm SEM for at least three independent experiments, and significance was considered when $p$ value was less than 0.05 .

\section{Results}

$\alpha$-Syn directly interacted with PP2A C $\alpha$ and upregulated its activity

Previous studies have shown that $\alpha$-Syn could interact with PP2A C $\alpha$ and upregulate PP2A activity $[17,40]$. To reproduce this effect, we firstly expressed and purified these two proteins. $\alpha$-Syn, with GST tag, was expressed in E.coli, and then purified by affinity chromatography with glutathione-sepharose beads (Fig. 1A). For PP2A C $\alpha$, it was expressed in recombinant insect baculovirus, and then purified by affinity chromatography with $\mathrm{Ni}$ sepharose beads combined with gel filtration chromatography (Fig. 1B). In order to confirm the direct interaction between $\alpha$-Syn and PP2A C $\alpha$, we performed GST pull-down assay after incubation of these two purified proteins. As shown in Fig. 1C, $\alpha$-Syn pulled down PP2A C $\alpha$, while no signal was observed in the GST group as control, demonstrating that $\alpha$-Syn could directly interact with PP2A C $\alpha$.

Subsequently, we detected the effect of $\alpha$-Syn on PP2A activity. For this purpose, $\alpha$-Syn protein was firstly obtained by cleaving the GST tag from the fusion protein of $\alpha$-Syn/GST

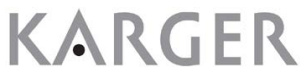


Fig. 1. $\alpha$-Syn interacted with PP2A $\mathrm{C} \alpha$ and upregulated its activity. (A-B) The purified $\alpha$-Syn protein (A) and PP2A $\mathrm{C} \alpha$ protein $(\mathrm{B})$ were detected by the coomassie brilliant blue (CBB) staining of SDS-PAGE gels. (C) The interaction between $\alpha$-Syn and PP2A C $\alpha$ was detected by GST pulldown assay. Purified $\alpha$-Syn protein was incubated with PP2A C $\alpha$ protein, then the compounds were separated by SDS-PAGE gels. Anti-His and anti-GST blots showed input and pull-down fractions in GST pull-down assay. Input, PP2A C $\alpha$. (D) Purified $\alpha$-Syn protein was incubated with PP2A $\mathrm{C} \alpha$ for $0.5 \mathrm{~h}$, then PP2A activity was detected using colorimetric assay. ${ }^{* *} \mathrm{p}<0.01, \mathrm{n}=5$. (E) The plasmids $\mathrm{pCMV}$ myc- $\alpha$-Syn and pCMV-myc were transiently transfected into SK-N-SH cells for $24 \mathrm{~h}$. The protein level of $\alpha$-Syn was detected by western blotting. $\beta$-actin was used as a loading control (F) $24 \mathrm{~h}$ after plasmid transfection into

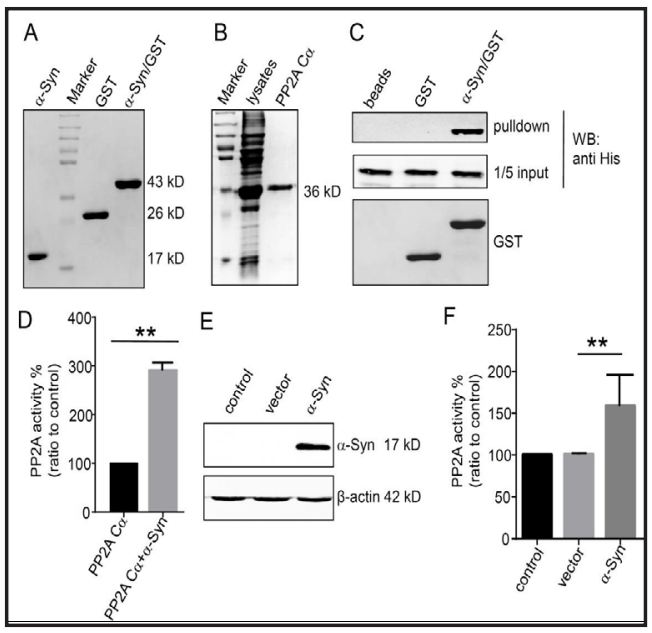
SK-N-SH cells, the PP2A activity regulation by $\alpha$-Syn was detected by colorimetric assay. ${ }^{* *} \mathrm{p}<0.01, \mathrm{n}=5$.

(Fig. 1A). Then $\alpha$-Syn protein $(0.5 \mathrm{mg} / \mathrm{ml})$ was incubated with PP2A C $\alpha(0.5 \mathrm{mg} / \mathrm{ml})$, and PP2A activity was measured by colorimetric assay. As shown in Fig. 1D, the PP2A activity in response to $\alpha$-Syn was two-fold higher than the baseline PP2A activity, which implied that $\alpha$-Syn could upregulate PP2A activity. To further confirm the above results in cells, the plasmids pCMV-myc- $\alpha$-Syn and the empty plasmids pCMV-myc were transiently transfected into SK-N-SH cells respectively. First, the protein level of $\alpha$-Syn was detected by western blotting to make sure they were at comparable level. (Fig. 1E). Then the effect of $\alpha$-Syn on PP2A activity was detected. The results showed that the PP2A activity in $\alpha$-Syn-transfected group was larger than that in blank vector group and non-treatment group, which suggested that $\alpha$-Syn could upregulate PP2A activity in cells (Fig. 1F). Together, the results indicated that $\alpha$-Syn could directly interact with PP2A C $\alpha$ and upregulate its activity.

\section{The NAC domain of $\alpha$-Syn directly interacted with PP2A C $\alpha$}

$\alpha$-Syn is usually divided into three domains: the $\mathrm{N}$ terminus (residues $1-60$ ), the NAC domain (residues 61-95), and the $C$ terminus (residues 96-140) (Fig. 2A) [7, 8, 43]. Since the above experiments indicated that $\alpha$-Syn could directly interact with PP2A $\mathrm{C} \alpha$, we questioned which terminus of $\alpha$-Syn was associated with its interaction with PP2A C $\alpha$. To address this question, $\alpha$-Syn truncates were constructed, expressed in E.coli, and purified by affinity chromatography with glutathione-sepharose beads (Fig. 2B). Then we detected the interaction between $\alpha$-Syn truncates and PP2A C $\alpha$ by GST pull-down assay. The results showed that the NAC domain of $\alpha$-Syn pulled down PP2A C $\alpha$, while the N terminus and C terminus could not (Fig. 2C). Statistically, the level of PP2A C $\alpha$, pulled down by the NAC domain and full length $\alpha$-Syn, were significantly higher compared with the other groups (Fig. 2D). To further confirm this observation, we then replaced the NAC domain of $\alpha$-Syn with the homologous region from $\beta$-Syn to get the chimera $\alpha$-Syn-NAC-swap. Since it demonstrated that the NAC domain was responsible for $\alpha$-Syn to interact with PP2A C $\alpha$, we hypothesized that the chimera $\alpha$-Syn-NAC-swap should not exhibit its interaction with PP2A C $\alpha$. Indeed, our GST pull-down experiment indicated that the chimera $\alpha$-Syn-NAC-swap could not pull down the protein of PP2A C $\alpha$ (Fig. 2E-F). Together, these results suggested the NAC domain of $\alpha$-Syn could directly interact with PP2A C $\alpha$.

The NAC domain of $\alpha$-Syn was responsible for the PP2A activity regulation

Since the NAC domain of $\alpha$-Syn could directly interact with PP2A C $\alpha$, then we asked if it could also upregulate the activity of PP2A. For this purpose, the purified $\alpha$-Syn truncated proteins $(0.5 \mathrm{mg} / \mathrm{ml})$ were incubated with PP2A C $\alpha(0.5 \mathrm{mg} / \mathrm{ml})$ respectively, then PP2A activity was measured by colorimetric assay. As shown in Fig. 3A, the PP2A activity in the 
groups of $\alpha$-Syn and $\alpha$-Syn-NAC was higher than the baseline PP2A activity, while the PP2A activity in the group of $\alpha-S y n-N$ and $\alpha$-Syn-C was similar with the baseline. These data implied that the NAC domain of $\alpha$-Syn could upregulate PP2A activity, but the $\mathrm{N}$ and $\mathrm{C}$ terminus had almost no effect on PP2A activity.

To further confirm the effect of $\alpha$-Syn truncations on PP2A activity in cells, the plasmids encoding $\alpha$-Syn truncations were transiently transfected into SK-N-SH cells. First, the expression level of $\alpha$-Syn truncations in transfected cells was confirmed by immunocytochemistry (Fig. 3B) and dot blotting (Fig. 3C). Then PP2A activity in transfected cells was measured by the colorimetric assay, and the results showed that the PP2A activity in full length $\alpha$-Syn and $\alpha$-Syn-NAC-transfected cells were larger than that in vector-transfected cells, while the PP2A activity in the $\alpha$-Syn- $\mathrm{N}$ and $\alpha$-Syn-C-transfected cells was similar

Fig. 2. The NAC domain of $\alpha$-Syn interacted with PP2A C $\alpha$. (A) The model of $\alpha$-Syn truncations. (B) The purified proteins of $\alpha$-Syn truncations were detected by CBB staining of SDS-PAGE gels. (C) GST pulldown assay was performed to detect the interaction between $\alpha$-Syn truncations and PP2A C $\alpha$. Purified $\alpha$-Syn truncates were incubated with PP2A C $\alpha$, then the compounds were separated by SDS-PAGE gels. Anti-His and anti-GST blots showed input and pulldown fractions in GST pull-down assay. Input, PP2A C $\alpha$. (D) Quantitative analysis of the percentage of PP2A $C \alpha$ pull-down by $\alpha$-Syn truncations was performed. (E) After replacing the NAC domain of $\alpha$-Syn with the homologous region from $\alpha$-Syn to get the chimera $\alpha$-Syn-NAC-swap, the interaction between this chimera and PP2A C $\alpha$ was analyzed by GST pull-down assay. The purified chimera protein $\alpha$-Syn-NAC-swap was incubated with PP2A C $\alpha$, then the compounds were separated by SDS-PAGE gels. Anti-His and anti-GST blots showed input and pulldown fractions in GST pull-down assay. Input, PP2A

$\mathrm{C} \alpha$. (F) Quantitative analysis of the percentage of PP2A C $\alpha$ pull-down by $\alpha$-Syn-NCA-swap was performed. ${ }^{* *} \mathrm{p}<0.01, \mathrm{n}=5$.

Fig. 3. The NAC domain of $\alpha$-Syn upregulated the activity of PP2A. (A) The purified full length $\alpha$-Syn and its truncations were incubated with PP2A $\mathrm{C} \alpha$ for $0.5 \mathrm{~h}$, then PP2A activity was detected by colorimetric assay. ${ }^{* *} \mathrm{p}<0.01, \mathrm{n}=5$. (B) The plasmids of $\alpha$-Syn and its truncations (pCMV-myc- $\alpha$-Syn, pCMV-myc- $\alpha$-Syn-N, pCMV-myc- $\alpha$-Syn-M, pCMVmyc- $\alpha$-Syn-C) were transfected into SK-N-SH cells respectively. After transfection $24 \mathrm{~h}$, cells were fixed and stained with anti-myc antibodies (green). The nucleus was stained by DAPI (blue). Scale bar, $25 \mu \mathrm{m}$. (C) The protein level of $\alpha$-Syn and its truncations in SK-N-SH cells was detected by dot blotting after transfection for $24 \mathrm{~h}$. (D) $24 \mathrm{~h}$ after transfection of $\alpha$-Syn and its truncation plasmids into SK-N-SH cells, PP2A activity was detected by colorimetric assay. ${ }^{* *} \mathrm{p}<0.01, \mathrm{n}=5$.
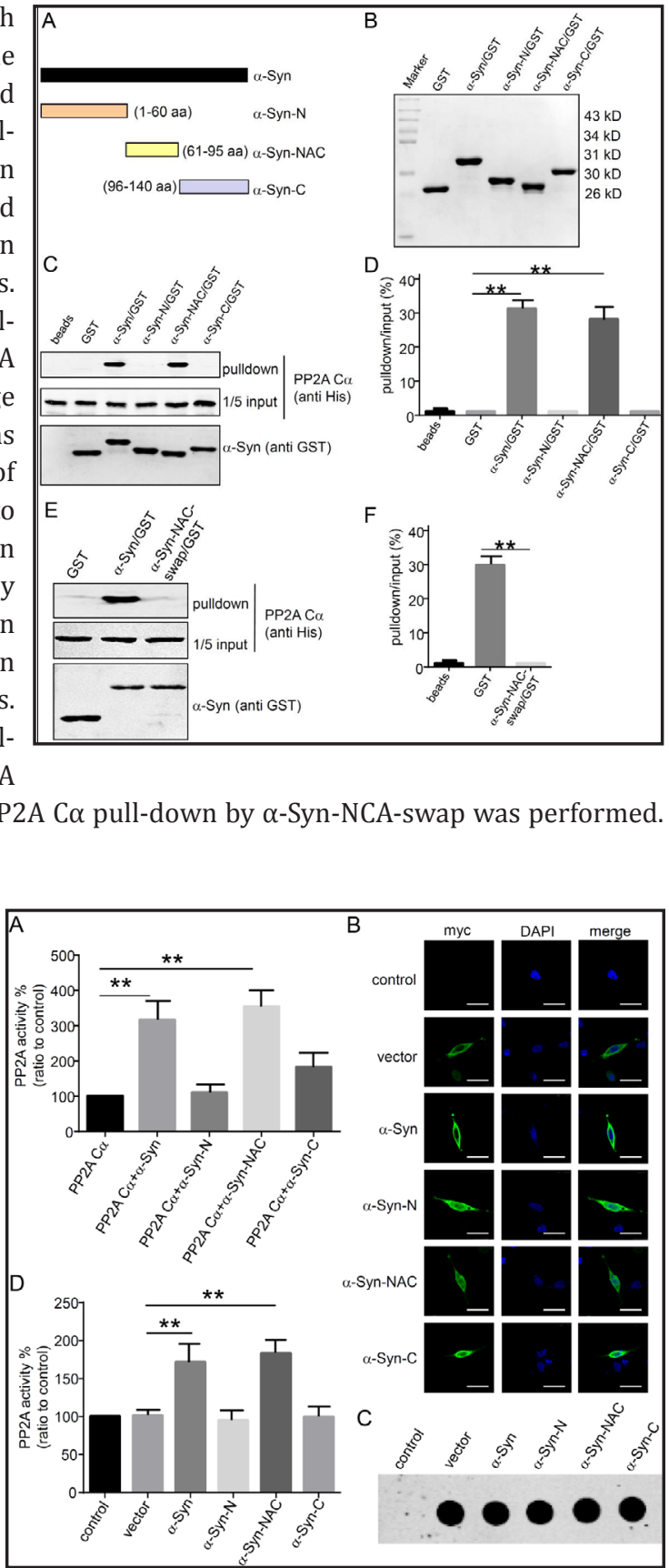
with that in vector-transfected group (Fig. 3D). The above results suggested that the NAC domain of $\alpha$-Syn, like the full length of $\alpha$-Syn, could upregulate PP2A activity, while the $N$ and $\mathrm{C}$ terminus could not. These data confirmed that the NAC domain of $\alpha$-Syn, containing the hydrophobic amino acid, was responsible for regulating PP2A activity, which was consistent with the results in vitro.

\section{Blocking the NAC domain of $\alpha$-Syn declined its regulating effect on PP2A activity}

Since the NAC domain of $\alpha$-Syn could upregulate PP2A activity, we hypothesized that blocking the NAC domain might decline its regulating effect on the activity of PP2A. As we know, $\alpha$-Syn is a natively unfolded protein with a tendency to aggregate by the hydrophobic interaction $[8,13,44]$. After aggregation, the hydrophobic domain of $\alpha$-Syn may be blocked, so $\alpha$-Syn aggregates should less upregulate the PP2A activity than monomers. To test our hypothesis, $\alpha$-Syn aggregates were firstly generated from purified recombinant $\alpha$-Syn in vitro at $37^{\circ} \mathrm{C}$ for $72 \mathrm{~h}$ with continuous shaking. Electron microscope imaging further verified the morphology of $\alpha$-Syn aggregates, and the results showed $\alpha$-Syn aggregates were large, broad and had a ribbon-like shape fibrils, but the fibril-like structure were not detected in $\alpha$-Syn monomer sample (Fig. 4A). Then the PP2A activity in response to $\alpha$-Syn aggregates was measured by colorimetric assay, and the results showed that PP2A activity response to $\alpha$-Syn aggregates was much lower than that of $\alpha$-Syn monomers, indicating that aggregates could less stimulate PP2A activity than monomers (Fig. 4B).

Next, we further confirm that $\alpha$-Syn aggregates less stimulated the PP2A activity than monomers in cells. A53T, the first mutant of $\alpha$-Syn associated with PD, had a more propensity to form aggregates [45], and we also further confirmed that A53T mutant could form aggregates more efficiently than WT $\alpha$-Syn in vitro (Fig. 4C). So, we speculated that A53T could less upregulate PP2A activity in cells, compared with wild type (WT) $\alpha$-Syn. In this scenario, we first adopted a protein-fragment complementation assay (PCA) to prove that A53T was more prone to aggregate than WT $\alpha$-Syn. For this purpose, WT $\alpha$-Syn or A53T mutant were fused to the amino-terminal (1-93) or carboxy-terminal (94-169) fragments of Gaussia princeps luciferase (GLuc) respectively [46], to generate $\alpha$-Syn-GLuc-N, $\alpha$-Syn-GLuc-C or A53T-GLuc-N, A53T-GLuc-C constructs. The two paired fusion proteins could reconstitute when brought together during $\alpha$-Syn aggregation $[47,48]$ (Fig. 5A). So the SK-N-SH cells may be transfected with these paired constructs for analysing the $\alpha$-Syn aggregation level. First, to evaluate the expression level of these proteins, we adopted the western blotting and the results indicated that the levels of these proteins were similar on immunoblots (Fig. 5B). After

Fig. 4. $\alpha$-Syn aggregates could less stimulate PP2A activity than monomers. (A) Electron microscope images of $\alpha$-Syn monomers (the upper) and aggregates (the lower). Scale bar, $200 \mathrm{~nm}$. (B) $\alpha$-Syn aggregates and monomers were incubated with PP2A C $\alpha$ for 0.5 h respectively, then PP2A activity was detected in vitro by colorimetric assay kit. (C) Kinetic analysis of the aggregation of $\alpha$-Syn and its mutant A53T using thioflavin T (ThT) fluorescence assay. $\alpha$-Syn and its mutant A53T proteins were dissolved to a concentration of $360 \mu \mathrm{M}$ (around $5 \mathrm{mg} / \mathrm{mL}$ ) respectively in the assembly buffer (50

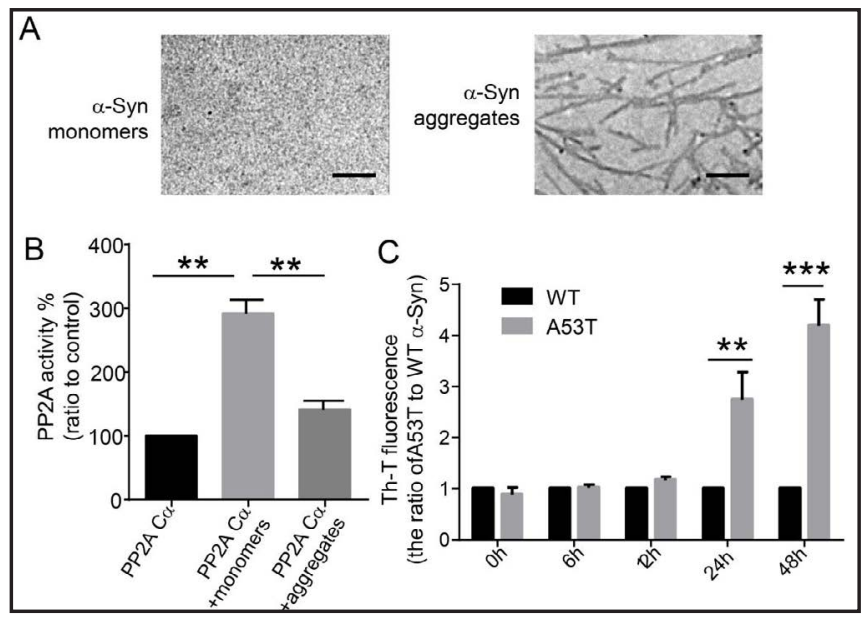
$\mathrm{mM}$ Tris/100 mM NaCl, pH 7.0). The reaction mixtures were incubated at $37^{\circ} \mathrm{C}$ with constant agitation $(1000 \mathrm{rpm})$ for two days and the rate of aggregation was monitored using the ThT fluorescence assay (excitation at $450 \mathrm{~nm}, 2.5 \mathrm{~nm}$ slit, and emission at $480 \mathrm{~nm}, 5 \mathrm{~nm}$ slit). ${ }^{* *} \mathrm{p}<0.01, \mathrm{n}=5$. 
injection of cell permeable substrate, we analyzed the aggregation level by PCA assay. The results showed the luciferase activity of cells cotransfected with A53TGLuc-N/C was larger than that of cells cotransfected with $\alpha$-Syn-GLuc-N/C (Fig. 5C). These date suggested A53T was more prone to aggregate than WT $\alpha$-Syn.

Since A53T was more prone to aggregate than WT $\alpha$-Syn, we then tested our hypothesis that A53T could less stimulate PP2A activity than WT $\alpha$-Syn in cells. The plasmids pCMV-myc- $\alpha$-Syn and pCMV-myc-A53T were transfected into SK-N-SH cells respectively, and the expression level of WT $\alpha$-Syn and A53T in transfected cells was first confirmed to be at the comparable level by immunocytochemistry (Fig. 6A) and western blotting (Fig. 6B). Then we measured PP2A activity in transfected cells, and the results showed that the PP2A activity in cells transfected with A53T was lower than that in cells transfected with WT $\alpha$-Syn (Fig. 6C). These results implied that A53T less stimulated PP2A activity than WT $\alpha$-Syn in cells.

Certainly, for this effect that A53T less stimulated PP2A activity than WT $\alpha$-Syn in cells, there are two possibilities: one possibility is that A53T mutation per se has less effect on PP2A activity upregulation, and the other possibility is that A53T forms more aggregates and consequently blocks the hydrophobic domain of $\alpha$-Syn which is associated with the PP2A activity upregulation. Thus, we have to exclude one possibility from the other. To test the effect of A53T mutation per se on the PP2A activity, we first expressed and purified A53T protein (Fig. 7A). WT $\alpha$-Syn and A53T proteins were incubated with PP2A $\mathrm{C} \alpha$ protein respectively, and the results showed that the PP2A activity in response to purified A53T protein was similar with that of WT $\alpha$-Syn (Fig. 7B). These results indicated that A53T mutation per se had similar regulating effect on PP2A activity with WT $\alpha$-Syn, and the effect that A53T less stimulated PP2A activity than WT $\alpha$-Syn in cells may be due to the formation of more aggregates in A53T transfecting cells.

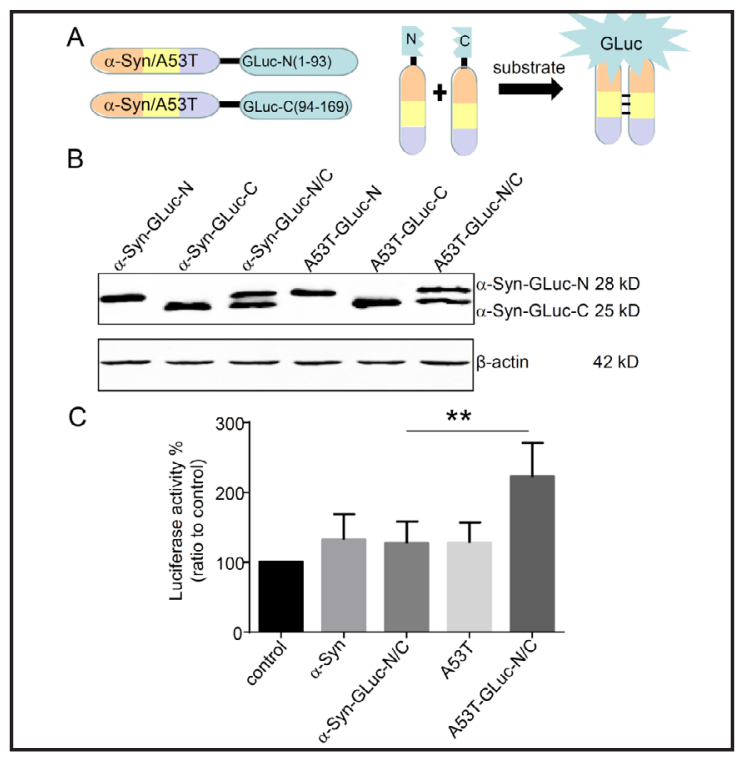

Fig. 5. A53T was more prone to aggregate than WT $\alpha$-Syn. (A) The principle of protein-fragment complementation assay based on Gaussia princeps luciferase. (B) The protein levels, after paired constructs transfected into SK-N-SH cells, were detected by western blotting. $\beta$-actin was used as a loading control. (C) $24 \mathrm{~h}$ after transfection, the cells were washed and treated with the substrates (coelenterazine, $20 \mu \mathrm{M}$ ). The luciferase activity was measured in an automated plate reader at $480 \mathrm{~nm}$. ${ }^{* *} \mathrm{p}<0.01, \mathrm{n}=5$.

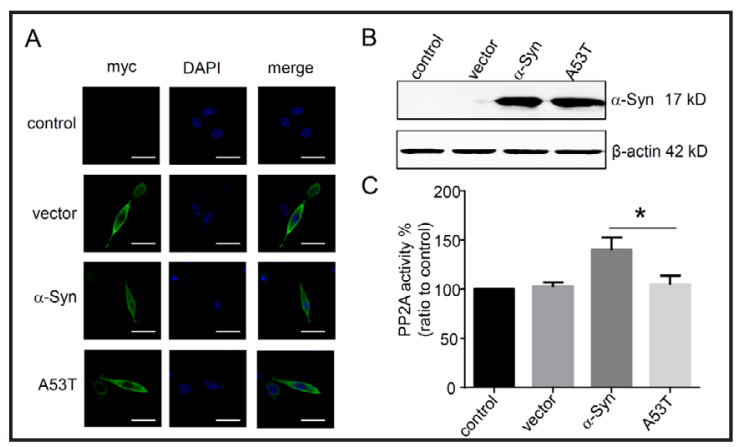

Fig. 6. A53T less stimulated the activity of PP2A than WT $\alpha$-Syn in cells. (A) The plasmids of $\alpha$-Syn (pCMV-myc- $\alpha-S y n$ ) and A53T (pCMV-myc-A53T) were transfected into SK-N-SH cells. After transfection 24 $\mathrm{h}, \mathrm{SK}-\mathrm{N}-\mathrm{SH}$ cells were fixed and stained with antimyc antibodies (green). The nucleus was stained by DAPI (blue). Scale bar, $25 \mu \mathrm{m}$. (B) Western blotting was performed to determine $\alpha$-Syn and A53T protein expression levels in transfected SK-N-SH cells. $\beta$-actin was used as a loading control. (C) $24 \mathrm{~h}$ after transfection with plasmids into SK-N-SH cells, PP2A activity was detected by colorimetric assay. ${ }^{*} \mathrm{p}<0.05, \mathrm{n}=5$. 


\section{Cellular Physiology Cell Physiol Biochem 2018;47:2613-2625

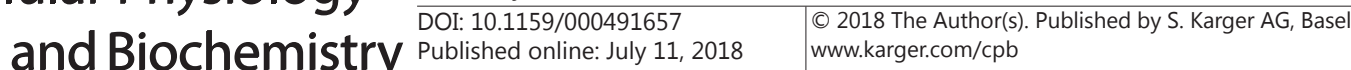 \\ Qu et al.: Alpha-Synuclein Upregulating Protein Phosphatase 2A Activity}

Together, the above results suggested that blocking the NAC domain of $\alpha$-Syn declined the upregulating effect on PP2A activity. In other words, the NAC domain was involved in the process of $\alpha$-Syn regulating PP2A activity.

The residue I123 in PP2A C $\alpha$ played a role in its activity upregulation by $\alpha$-Syn

Since the NAC domain of $\alpha$-Syn interacted with PP2A C $\alpha$ and upregulated its activity, but it is not clear which site of PP2A C $\alpha$ is responsible for its interaction with $\alpha$-Syn. There is a hydrophobic region in PP2A C $\alpha$ [21], since our results showed that the hydrophobic domain of $\alpha$-Syn (NAC) could bind to PP2A C $\alpha$, we hypothesized that $\alpha$-Syn might bind to the hydrophobic region of PP2A C $\alpha$ and upregulate its activity. To test our hypothesis, the computational molecular docking was firstly performed to imitate the potential interaction between $\alpha$-Syn and PP2A C $\alpha$. The docking results showed that the interaction was mainly clustered in the vicinity of I123 in PP2A C $\alpha$ and the end of the NAC terminus of $\alpha$-Syn (Fig. 8).

In order to further experimentally identify which site are responsible for PP2A C $\alpha$ upregulation by $\alpha$-Syn, five amino acids in the hydrophobic region of PP2A C $\alpha$ were mutated to hydrophilic acid, resulting in mutants I123S, W200S, L243S, Y265S and C269S (Fig. 9A). These mutants were expressed in recombinant insect baculovirus, and purified by affinity chromatography with $\mathrm{Ni}$-sepharose beads combined with gel filtration chromatography (Fig. 9B). Then these mutant proteins were respectively incubated with $\alpha$-Syn, and the interaction was detected by the GST pull-down assay. As shown in Fig. 9C, the mutants of PP2A $\mathrm{C} \alpha$ (including W200S, L243S, Y265S and C269S) were pulled down by $\alpha$-Syn, except I123S. These results implied that the I123 of PP2A $\mathrm{C} \alpha$ might be critical residue mediating the interaction between $\alpha$-Syn and PP2A C $\alpha$.

Since PP2A C $\alpha$ I123S could not bind to $\alpha$-Syn, we hypothesized $\alpha$-Syn might have less effect on its activity stimulation. So the purified $\alpha$-Syn protein $(0.5 \mathrm{mg} /$ $\mathrm{ml})$ and PP2A $\mathrm{C} \alpha$ I123S $(0.5 \mathrm{mg} / \mathrm{ml})$ were incubated in vitro, and then PP2A activity in response to $\alpha$-Syn was detected by the colorimetric assay. The results showed that the PP2A C $\alpha$ I123S activity in response to $\alpha$-Syn was similar with the baseline activity (Fig. 9D). Here, there are two possibilities for this observation: one possibility is that I123S mutation per se has effect on its activity, and the other possibility is that $\alpha$-Syn does not interact with I123S and consequently block the PP2A activity regulation by $\alpha$-Syn.

In order to exclude the effect of mutant (I123S) of PP2A C $\alpha$ per se on its activity, we compared the activity of PP2A C $\alpha$ I123S and WT PP2A C $\alpha$. As shown in Fig. 9D, the activity of I123S was comparable as the baseline PP2A activity.

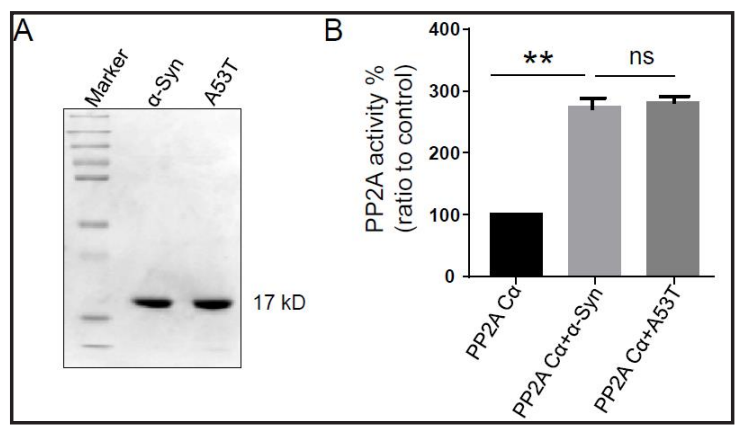

Fig. 7. A53T protein showed similar effect on PP2A activity with WT $\alpha$-Syn. (A) Purified A53T protein was detected by the CBB staining of SDS-PAGE gels. (B) Purified A53T protein and WT $\alpha$-Syn protein were incubated with PP2A $\mathrm{C} \alpha$ for $0.5 \mathrm{~h}$ respectively, then PP2A activity was detected in vitro by the assay kit. ${ }^{* *} \mathrm{p}<0.01, \mathrm{n}=5$.

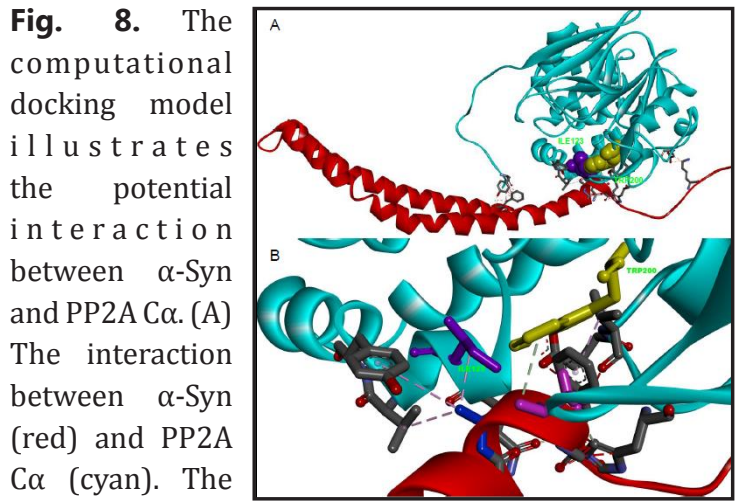

intermolecular

non-bond interaction between these two proteins were identified by using the Discovery Studio Visualizer. The interaction is mainly clustered in the vicinity of ILE123 of PP2A C $\alpha$ and the end of the NAC domain of $\alpha$-Syn. (B) The close view of the interaction between $\alpha$-Syn and PP2A C $\alpha$. 
In other words, I123S per se could not affect the PP2A activity. The above results together suggested that the residue I123 in PP2A C $\alpha$ might play a role in its binding with $\alpha$-Syn and its activity upregulation, although we could not exclude other residues which were potential for this effect.

\section{Discussion}

In this study, we explored the molecular mechanism of $\alpha$-Syn regulating PP2A activity. We found the NAC domain of $\alpha$-Syn could interact with PP2A C $\alpha$ and increased its activity. When the NAC domain was blocked during $\alpha$-Syn aggregation, $\alpha$-Syn showed little effect on PP2A activity upregulation. In addition, we found the residue I123 of PP2A C $\alpha$ might play a role in its activity regulation by $\alpha$-Syn. Together, these results implied that $\alpha$-Syn might bind to PP2A $\mathrm{C} \alpha$ by hydrophobic interaction and upregulate PP2A activity, and $\alpha$-Syn aggregates could less stimulate the PP2A activity than $\alpha$-Syn monomers. These findings could be best illustrated in Fig. 10 in terms of the protein binding pattern and PP2A activity regulation.

We found that the NAC domain of $\alpha$-Syn could interact with PP2A C $\alpha$, but the $\mathrm{N}$ terminus and $\mathrm{C}$ terminus could not. From theoretical perspective, the NAC terminus of $\alpha$-Syn is a hydrophobic region, and it can bind to many moleculars and regulate their activity $[6,9,44]$.

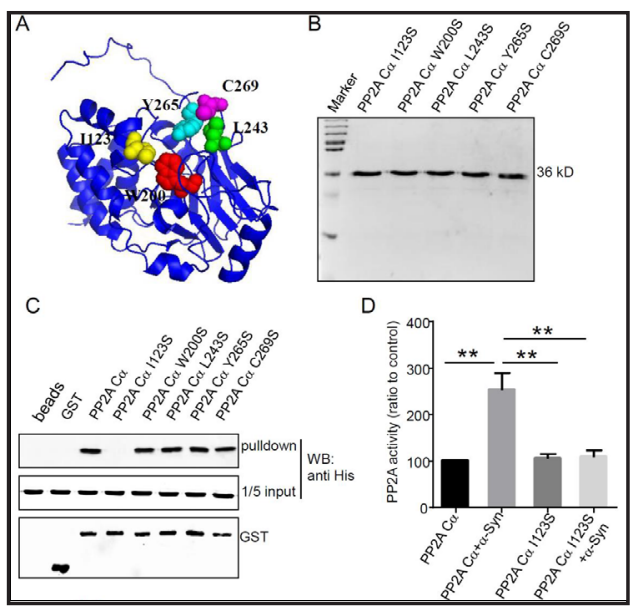

Fig. 9. The residue I123 of PP2A C $\alpha$ might play a role in its activity upregulation by $\alpha$-Syn. (A) Schematic representation of I123, W200, L243, Y265 and C269 residues in PP2A C $\alpha$. (B) The purified PP2A C $\alpha$ mutants (including I123S, W200S, L243S, Y265S and C269S) were detected by the CBB staining of SDS-PAGE gels. (C) GST pull-down assay was performed to detect the interaction between $\alpha$-Syn and PP2A C $\alpha$ mutants. Purified $\alpha$-Syn protein were incubated with PP2A C $\alpha$ mutant proteins, then the compounds were separated by SDS-PAGE gels. Anti-His and anti-GST blots showed input and pull-down fractions in GST pull-down assay. Input, PP2A C $\alpha$. (D) $\alpha$-Syn and PP2A C $\alpha$ I123S were incubated together, then PP2A activity was detected by colorimetric assay kit. * $\mathrm{p}<0.05$, ${ }^{* *} \mathrm{p}<0.01, \mathrm{n}=5$. Here, we found that the NAC domain of $\alpha$-Syn could interact with PP2A C $\alpha$ and upregulate its activity. On the other side, PP2A is an important phosphatase, and the hydrophobic region of PP2A C $\alpha$ plays a chief role in its activity regulation. As is known, there is also a hydrophobic region in PP2A C $\alpha$. Previous studies have shown that okadaic acid, an inhibitor of PP2A, could bind to the hydrophobic region of PP2A C $\alpha$ to inhibit its activity. Further, from the homology model, the interaction between $\alpha$-Syn and PP2A C $\alpha$ was mainly clustered in the NAC domain of $\alpha$-Syn and the vicinity of I123 of PP2A C $\alpha$. So we hypothesized that the NAC domain of $\alpha$-Syn might bind to the hydrophobic region of PP2A C $\alpha$. Experimentally, our data indeed showed that the NAC domain of $\alpha$-Syn could bind to the hydrophobic region of PP2A $\mathrm{C} \alpha$ and upregulate its activity, particularly the residue I123 of PP2A C $\alpha$.

$\alpha$-Syn is a natively unfolded protein which is prone to aggregate, and $\alpha$-Syn aggregates are formed by the NAC domain which mediates the conformational changes from random coil to a $\beta$-sheet structure [6]. Aggregated $\alpha$-Syn is the major component of inclusions in PD and other synucleinopathy brains, which indicates that $\alpha$-Syn aggregation is relevant to the pathogenesis of neurodegenerative diseases $[8,49]$. We found $\alpha$-Syn aggregates, blocking the NAC domain, could less upregulate PP2A activity than $\alpha$-Syn monomers. Previous studies have shown the loss of PP2A activity was associated with $\alpha$-Syn aggregation in DLB brain and $\alpha$-Syn triplication brain, which was consistent with our findings.

A53T, the first point mutation related to $\mathrm{PD}$, is prone to form aggregates by blocking the NAC domain to exhibit toxicity $[9,50]$. In our study, we indeed confirmed A53T was 


\section{Cellular Physiology Cell Physiol Biochem 2018;47:2613-2625 \\ \begin{tabular}{l|l} 
DOI: 10.1159/000491657 & O 2018 The Author(s). Published by S. Karger AG, Basel \\
www.karger.com/cpb
\end{tabular} \\ Qu et al.: Alpha-Synuclein Upregulating Protein Phosphatase 2A Activity}

more prone to aggregate than WT $\alpha$-Syn using PCA, consequently we found A53T could less upregulate PP2A activity than WT $\alpha$-Syn. Previous studies have shown that aging A53T mice exhibited $\alpha$-Syn aggregation in olfactory and adrenal, and aggregated A53T $\alpha$-Syn is a poor stimulator of PP2A activity [50], which was consistent with our findings. These data further suggested the NAC domain of $\alpha$-Syn bound to PP2A $\mathrm{C} \alpha$ and upregulated its activity.

PP2A plays essential roles in neurodegenerative diseases. In $\mathrm{PD}$, the upregulation of PP2A activity could reduce the TH phosphorylation to decrease the dopamine synthesis and increase the motor

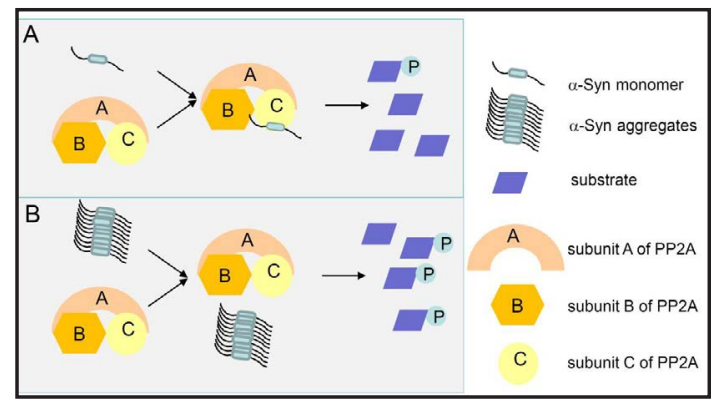

Fig. 10. A proposed model of $\alpha$-Syn regulating PP2A C $\alpha$ activity. (A) $\alpha$-Syn binds to the PP2A C $\alpha$ by hydrophobic interaction and regulates its activity. (B) $\alpha$-Syn aggregates, in which the hydrophobic domain was blocked, could less stimulate the activity of PP2A than monomers. deficits. Since we found the NAC domain of $\alpha$-Syn could bind to the hydrophobic center of PP2A C $\alpha$ and upregulate its activity, blocking the NAC domain of $\alpha$-Syn or occupying the hydrophobic center of PP2A C $\alpha$ would be potential therapeutic methods of $\mathrm{PD}$, since increasing the dopamine synthesis and alleviating the motor symptoms.

\section{Acknowledgements}

This work was supported by Grants from the National Natural Science Foundation of China (31571202, 31271136, 81371398), the Importation and Development of High-Caliber Talents Project of Beijing Municipal Institutions (CIT\&TCD201504087), the Clinic-Basic Fund of Capital Medical University (17JL34), and the Project of Construction of Innovative Teams and Teacher Career Development for Universities and Colleges Under Beijing Municipality (IDHT20140514).

\section{Disclosure Statement}

The authors declare that they have no conflict of interests.

\section{References}

1 Devine MJ, Gwinn K, Singleton A, Hardy J: Parkinson's disease and alpha-synuclein expression. Mov Disord 2011;26:2160-2168.

-2 Zhang H, Liu J, Wang X, Duan C, Wang X, Yang H: V63 and N65 of overexpressed alpha-synuclein are involved in mitochondrial dysfunction. Brain Res 2016;1642:308-318.

-3 Spillantini MG, Schmidt ML, Lee VM, Trojanowski JQ Jakes R, Goedert M: Alpha-synuclein in Lewy bodies. Nature 1997;388:839-840.

4 Pringsheim T, Jette N, Frolkis A, Steeves TD: The prevalence of Parkinson's disease: a systematic review and meta-analysis. Mov Disord 2014;29:1583-1590.

5 Luk KC, Kehm V, Carroll J, Zhang B, O’Brien P, Trojanowski JQ, Lee VM: Pathological alpha-synuclein transmission initiates Parkinson-like neurodegeneration in nontransgenic mice. Science 2012;338:949953.

6 Lawand NB, Saade NE, El-Agnaf OM, Safieh-Garabedian B: Targeting alpha-synuclein as a therapeutic strategy for Parkinson's disease. Expert Opin Ther Targets 2015;19:1351-1360. 


\section{Cellular Physiology Cell Physiol Biochem 2018;47:2613-2625 \begin{tabular}{l|l} 
DOI: 10.1159/000491657 & $\begin{array}{l}\text { O 2018 The Author(s). Published by S. Karger AG, Basel } \\
\text { www.karger.com/cpb }\end{array}$
\end{tabular}}

7 McDowall JS, Brown DR: Alpha-synuclein: relating metals to structure, function and inhibition. Metallomics 2016;8:385-397.

-8 Dehay B, Bourdenx M, Gorry P, Przedborski S, Vila M, Hunot S, Singleton A, Olanow CW, Merchant KM, Bezard E, Petsko GA, Meissner WG: Targeting $\alpha$-synuclein for treatment of Parkinson's disease: mechanistic and therapeutic considerations. The Lancet Neurology 2015;14:855-866.

-9 Stefanis L: alpha-Synuclein in Parkinson's disease. Cold Spring Harb Perspect Med 2012;2:a009399.

10 Dettmer U, Selkoe D, Bartels T: New insights into cellular alpha-synuclein homeostasis in health and disease. Curr Opin Neurobiol 2016;36:15-22.

11 Shen J, Du T, Wang X, Duan C, Gao G, Zhang J, Lu L, Yang H: alpha-Synuclein amino terminus regulates mitochondrial membrane permeability. Brain Res 2014;1591:14-26.

-12 Proukakis C, Dudzik CG, Brier T, MacKay DS, Cooper JM, Millhauser GL, Houlden H, Schapira AH: A novel alpha-synuclein missense mutation in Parkinson disease. Neurology 2013;80:1062-1064.

13 Giasson BI, Murray IV, Trojanowski JQ, Lee VM: A hydrophobic stretch of 12 amino acid residues in the middle of alpha-synuclein is essential for filament assembly. J Biol Chem 2001;276:2380-2386.

14 Sato H, Kato T, Arawaka S: The role of Ser129 phosphorylation of alpha-synuclein in neurodegeneration of Parkinson's disease: a review of in vivo models. Rev Neurosci 2013;24:115-123.

15 Oueslati A, Fournier M, Lashuel HA: Role of post-translational modifications in modulating the structure, function and toxicity of alpha-synuclein: implications for Parkinson's disease pathogenesis and therapies. Prog Brain Res 2010;183:115-145.

16 Bendor JT, Logan TP, Edwards RH: The function of alpha-synuclein. Neuron 2013;79:1044-1066.

17 Peng X, Tehranian R, Dietrich P, Stefanis L, Perez RG: Alpha-synuclein activation of protein phosphatase 2A reduces tyrosine hydroxylase phosphorylation in dopaminergic cells. J Cell Sci 2005;118:3523-3530.

-18 Burre J, Sharma M, Tsetsenis T, Buchman V, Etherton MR, Sudhof TC: Alpha-synuclein promotes SNAREcomplex assembly in vivo and in vitro. Science 2010;329:1663-1667.

19 Wu J, Lou H, Alerte TN, Stachowski EK, Chen J, Singleton AB, Hamilton RL, Perez RG: Lewy-like aggregation of alpha-synuclein reduces protein phosphatase $2 \mathrm{~A}$ activity in vitro and in vivo. Neuroscience 2012;207:288-297.

-20 Xu Y, Xing Y, Chen Y, Chao Y, Lin Z, Fan E, Yu JW, Strack S, Jeffrey PD, Shi Y: Structure of the protein phosphatase 2A holoenzyme. Cell 2006;127:1239-1251.

21 Xing Y, Xu Y, Chen Y, Jeffrey PD, Chao Y, Lin Z, Li Z, Strack S, Stock JB, Shi Y: Structure of protein phosphatase 2A core enzyme bound to tumor-inducing toxins. Cell 2006;127:341-353.

22 Du TT, Wang L, Duan CL, Lu LL, Zhang JL, Gao G, Qiu XB, Wang XM, Yang H: GBA deficiency promotes SNCA/alpha-synuclein accumulation through autophagic inhibition by inactivated PPP2A. Autophagy 2015;11:1803-1820.

23 Wang Y, Liu J, Chen M, Du T, Duan C, Gao G, Yang H: The novel mechanism of rotenone-induced alphasynuclein phosphorylation via reduced protein phosphatase 2A activity. Int J Biochem Cell Biol 2016;75:3444.

-24 Cho US, Xu W: Crystal structure of a protein phosphatase 2A heterotrimeric holoenzyme. Nature 2007;445:53-57.

25 Xing Y, Li Z, Chen Y, Stock JB, Jeffrey PD, Shi Y: Structural mechanism of demethylation and inactivation of protein phosphatase 2A. Cell 2008;133:154-163.

-26 Saraf A, Oberg EA, Strack S: Molecular determinants for PP2A substrate specificity: charged residues mediate dephosphorylation of tyrosine hydroxylase by the PP2A/B' regulatory subunit. Biochemistry 2010;49:986-995.

27 Leal RB, Sim AT, Goncalves CA, Dunkley PR: Tyrosine hydroxylase dephosphorylation by protein phosphatase 2A in bovine adrenal chromaffin cells. Neurochem Res 2002;27:207-213.

-28 Letourneux C, Rocher G, Porteu F: B56-containing PP2A dephosphorylate ERK and their activity is controlled by the early gene IEX-1 and ERK. EMBO J 2006;25:727-738.

29 Xu C, Wang X, Zhu Y, Dong X, Liu C, Zhang H, Liu L, Huang S, Chen L: Rapamycin ameliorates cadmiuminduced activation of MAPK pathway and neuronal apoptosis by preventing mitochondrial ROS inactivation of PP2A. Neuropharmacology 2016;105:270-284. 


\section{Cellular Physiology Cell Physiol Biochem 2018;47:2613-2625 \begin{tabular}{l|l} 
DOI: 10.1159/000491657 & $\begin{array}{l}\text { O } 2018 \text { The Author(s). Published by S. Karger AG, Basel } \\
\text { www.karger.com/cpb }\end{array}$
\end{tabular} \\ Qu et al.: Alpha-Synuclein Upregulating Protein Phosphatase 2A Activity}

30 Sontag E, Nunbhakdi-Craig V, Lee G, Brandt R, Kamibayashi C, Kuret J, White CL, 3rd, Mumby MC, Bloom GS: Molecular interactions among protein phosphatase 2A, tau, and microtubules. Implications for the regulation of tau phosphorylation and the development of tauopathies. J Biol Chem 1999;274:2549025498.

-31 Martin L, Latypova X, Wilson CM, Magnaudeix A, Perrin ML, Terro F: Tau protein phosphatases in Alzheimer's disease: the leading role of PP2A. Ageing Res Rev 2013;12:39-49.

-32 Rahman MM, Rumzhum NN, Morris JC, Clark AR, Verrills NM, Ammit AJ: Basal protein phosphatase 2A activity restrains cytokine expression: role for MAPKs and tristetraprolin. Sci Rep 2015;5:10063.

-33 Wong PM, Feng Y, Wang J, Shi R, Jiang X: Regulation of autophagy by coordinated action of mTORC1 and protein phosphatase 2A. Nat Commun 2015;6:8048.

-34 Sun D, Buttitta L: Protein phosphatase 2A promotes the transition to G0 during terminal differentiation in Drosophila. Development 2015;142:3033-3045.

-35 Hein AL, Seshacharyulu P, Rachagani S, Sheinin YM, Ouellette MM, Ponnusamy MP, Mumby MC, Batra SK, Yan Y: PR55alpha Subunit of Protein Phosphatase 2A Supports the Tumorigenic and Metastatic Potential of Pancreatic Cancer Cells by Sustaining Hyperactive Oncogenic Signaling. Cancer Res 2016;76:2243-2253.

36 Wlodarchak N, Xing Y: PP2A as a master regulator of the cell cycle. Crit Rev Biochem Mol Biol 2016;51:162184.

-37 Rohn TT, Vyas V, Hernandez-Estrada T, Nichol KE, Christie LA, Head E: Lack of pathology in a triple transgenic mouse model of Alzheimer's disease after overexpression of the anti-apoptotic protein Bcl-2 J Neurosci 2008;28:3051-3059.

-38 Arif M, Kazim SF, Grundke-Iqbal I, Garruto RM, Iqbal K: Tau pathology involves protein phosphatase 2A in parkinsonism-dementia of Guam. Proc Natl Acad Sci U S A 2014;111:1144-1149.

-39 Liu R, Zhou XW, Tanila H, Bjorkdahl C, Wang JZ, Guan ZZ, Cao Y, Gustafsson JA, Winblad B, Pei JJ: Phosphorylated PP2A (tyrosine 307) is associated with Alzheimer neurofibrillary pathology. J Cell Mol Med 2008;12:241-257.

40 Lou H, Montoya SE, Alerte TN, Wang J, Wu J, Peng X, Hong CS, Friedrich EE, Mader SA, Pedersen CJ, Marcus BS, McCormack AL, Di Monte DA, Daubner SC, Perez RG: Serine 129 phosphorylation reduces the ability of alpha-synuclein to regulate tyrosine hydroxylase and protein phosphatase $2 \mathrm{~A}$ in vitro and in vivo. J Biol Chem 2010;285:17648-17661.

41 Fu J, Qin L, He T, Qin J, Hong J, Wong J, Liao L, Xu J: The TWIST/Mi2/NuRD protein complex and its essential role in cancer metastasis. Cell Res 2011;21:275-289.

42 Fu J, Yoon HG, Qin J, Wong J: Regulation of P-TEFb elongation complex activity by CDK9 acetylation. Mol Cell Biol 2007;27:4641-4651.

43 Ozansoy M, Basak AN: The central theme of Parkinson's disease: alpha-synuclein. Mol Neurobiol 2013;47:460-465.

44 Kalia LV, Kalia SK: alpha-Synuclein and Lewy pathology in Parkinson's disease. Curr Opin Neurol 2015;28:375-381.

45 Ingelsson M: Alpha-Synuclein Oligomers-Neurotoxic Molecules in Parkinson's Disease and Other Lewy Body Disorders. Front Neurosci 2016;10:408.

-46 Remy I, Michnick SW: A highly sensitive protein-protein interaction assay based on Gaussia luciferase. Nat Methods 2006;3:977-979.

47 Danzer KM, Ruf WP, Putcha P, Joyner D, Hashimoto T, Glabe C, Hyman BT, McLean PJ: Heat-shock protein 70 modulates toxic extracellular alpha-synuclein oligomers and rescues trans-synaptic toxicity. FASEB J 2011;25:326-336.

48 Danzer KM, Kranich LR, Ruf WP, Cagsal-Getkin O, Winslow AR, Zhu L, Vanderburg CR, McLean PJ: Exosomal cell-to-cell transmission of alpha synuclein oligomers. Mol Neurodegener 2012;7:42.

49 Vekrellis K, Xilouri M, Emmanouilidou E, Rideout HJ, Stefanis L: Pathological roles of alpha-synuclein in neurological disorders. Lancet Neurol 2011;10:1015-1025.

-50 Farrell KF, Krishnamachari S, Villanueva E, Lou H, Alerte TN, Peet E, Drolet RE, Perez RG: Nonmotor parkinsonian pathology in aging A53T alpha-synuclein mice is associated with progressive synucleinopathy and altered enzymatic function. J Neurochem 2014;128:536-546. 